\title{
Analysis of the Effect of Process Parameters on Part Wall Thickness Variation in Conventional Metal Spinning of Cr-Mn Austenitic Stainless Steels
}

\author{
Peter Šugár 1 - Jana Šugárová 1 - Ján Petrovič² \\ 1 Slovak University of Technology, Faculty of Materials Science and Technology, Slovakia \\ 2 Eiben, Co. Ltd., Slovakia
}

\begin{abstract}
Metal spinning is one of a number of flexible sheet forming processes which is a cost effective option for the production of parts with a very high strength to weight ratio. Although the wall thickness of the formed part in conventional spinning is generally considered to be nearly constant, a non uniform distribution of wall thickness is in fact observed. In this study, the wall thickness variation of a formed part made of Cr-Mn austenitic stainless steel was analysed. The thickness variation was measured using an optical 3D scanning method and the influence of mandrel speed, feed ratio and tool path profile (convex, concave and linear) on wall thickness variation was studied. A three-level full factorial design of the experiment and ANOVA (Analysis of Variance) were used. The results show that the maximal variation in wall thickness is observed in approximately half of the part wall height (thinning) and on the open end of the part (thickening). Feed ratio and roller path profile are statistically significant factors governing wall thickness variation. There was no obvious effect from the variation in mandrel speed on the thickness distribution.
\end{abstract}

Keywords: metal spinning, stainless steel, 3D optical scanning, wall thickness, ANOVA

Highlights

- Experimental study of conventional metal spinning of Cr-Mn austenitic stainless steel part.

- Analysis of spun part wall thickness distribution by optical 3D scanning method.

- Quantifying the significance of mandrel speed, feed ratio and tool path profile on the wall thickness variation by analysis of variance (ANOVA).

- Identification of strong statistical significance of the tool path profile and feed ratio effect on wall thickness variation.

\section{INTRODUCTION}

Conventional metal spinning is a technology based on the gradual shaping of a circular sheet over a mandrel through the action of a roller that produces localised pressure and moves axially over the outer surface of the sheet to produce a symmetrical product. This technology incorporates conventional spinning, shear spinning and tube spinning [1] and also a group of novel spinning processes, such as nonaxisymmetrical spinning, non-circular cross-section spinning and tooth-shaped spinning [2] and [3]. Due to the development of numerically controlled lathes, spinning is becoming a cost effective option for both medium and high volume production of parts with a very high strength to weight ratio. Moreover, it is possible to spin components with tight geometrical tolerances and to achieve high-quality surface integrity [4] to [6]. The process has a wide variety of applications including parts for the automotive and aerospace industries, parts such as centrifuges, funnels, tanks, parts for medical and gastronomy equipment, as well as parts for musical instruments and pieces of art.
Wall thickness variation is a major defect found in parts made from sheet metals that influences the intensity of part defects and may cause part failure [7]. The wall thickness of the formed part in conventional spinning is, in general, considered to be nearly constant [8]. In fact, a non-uniform distribution of wall thickness is observed and therefore the spinning process must be optimized in order to produce components with a minimal variation in wall thickness. Based on experimental studies that have been carried out up to date, the spun part thickness distribution depends mainly on the number of tool passes, the offset of each pass from the other [9], as well as the tool feed ratio [10], shape of produced part [11], roller noise radius [4] and [12], friction [13] and first toolpass trajectory [14] to [16]. Low feed rates, large nose radius and multi-pass spinning are recommended to achieve uniform part wall thickness. High offset values tend to reduce wall thickness [4] and [9] to [16].

A strong research effort has been made to study the effect of tool path profile on thickness variation. Kang et al. [14], Liu et al. [15] and Hayama et al. [16] reported that the first pass in conventional spinning

*Corr. Author's Address: Slovak University of Technology in Bratislava, Faculty of Materials Science and Technology, Jana Bottu 25, 91724 Trnava, 
played a decisive role in the final wall thickness variations. They also concluded that the linear tool path profile is less complicated and helps to reveal deformation characteristics. Concave paths are widely used, while convex paths are more suitable for producing convex cone shapes such as container heads.

Wang and Long [17] applied finite element analysis to study the effects of tool paths (linear, concave, convex, and combined curve) on the variation of wall thickness. They suggested that dominant inplane tensile radial strains may be the main reason for wall thinning. The authors also reported that in a multi-pass conventional spinning process the wall thickness decreased after each forward roller pass (the roller feeds towards the rim of the workpiece) and there are almost no thickness changes during the backward passes. Using a concave roller path tends to greatly reduce wall thickness of the spun part, while using a convex roller path helps to keep the original wall thickness unchanged. A greater curvature of the concave path would result in more thinning of the wall thickness of the part.

Essa and Hartley [18] and [19] applied a finite element model for their study of the thickness distribution of aluminium cylindrical cups produced by conventional spinning. They found that by using a roller path profile of an involute curve in the first pass followed by a linear path profile in the second pass, minimum sheet thinning and a more uniform stress distribution could be obtained.

Polyblank and Alwood in their study [20] showed that toolpath design in spinning involves finding a balance between the need for deformation and the avoidance of failure by wrinkling and thinning. They suggest that in order to reduce thinning during the metal spinning process, a greater number of less aggressive passes should be used.

Although knowledge about the mechanics of spinning, which helps us to understand the final properties of the spun parts, has been developed by systematic investigation of the process using both experimental and theoretical techniques, the possible causes of thinning in part wall thickness during conventional spinning are still not fully understood and a knowledge gap between academic research outcomes and industry requirements exists.

The present paper analyses the results of experimental investigations concerning the wall thickness distribution of spun parts made of $\mathrm{Cr}-\mathrm{Ni}$ austenitic stainless steel. The influence of mandrel speed, feed ratio and tool path profile on the spun parts wall thickness distribution was determined using statistical analysis.

\section{EXPERIMENTAL SETUP AND METHODS}

\subsection{Experimental Samples and Set-Up}

For the production of the experimental samples, whose shape and dimensions are shown in Fig. 1, a circular blank with an outer diameter of $D_{0}=200 \mathrm{~mm}$, prepared by AWJ machining technology, was used. The sheet used was made of austenitic stainless steel $\mathrm{X} 5 \mathrm{CrNi18}$-10 (DIN 1.4301). The basic mechanical properties that define the material plasticity (ultimate tensile strength $\left(R_{m}\right), 0.2 \%$ proof strength $\left(R_{p 0.2}\right)$ and elongation $\left.\left(A_{80}\right)\right)$ of the experimental material is shown in Table 1.

Table 1. Mechanical properties of the experimental material

\begin{tabular}{cccc}
\hline$R_{m}[\mathrm{MPa}]$ & $R_{p 0.2}[\mathrm{MPa}]$ & $R_{p 0.2} / R_{m}[-]$ & $A_{80}[\%]$ \\
\hline 604 & 235 & 0.39 & 59.7 \\
\hline
\end{tabular}

The experimental samples were produced on a DENN spinning machine, type Zenn-80 equipped with a Sinumeric 840-D CNC control unit (Fig. 2).

The mandrel made of Cr-Mo alloy steel (X155CrVMo12-1) with a hardness of $56 \pm 2$ HRC and a forming roller also made of Cr-Mo alloy steel (X155CrVMo12-1) with a hardness of 54 HRC was used.
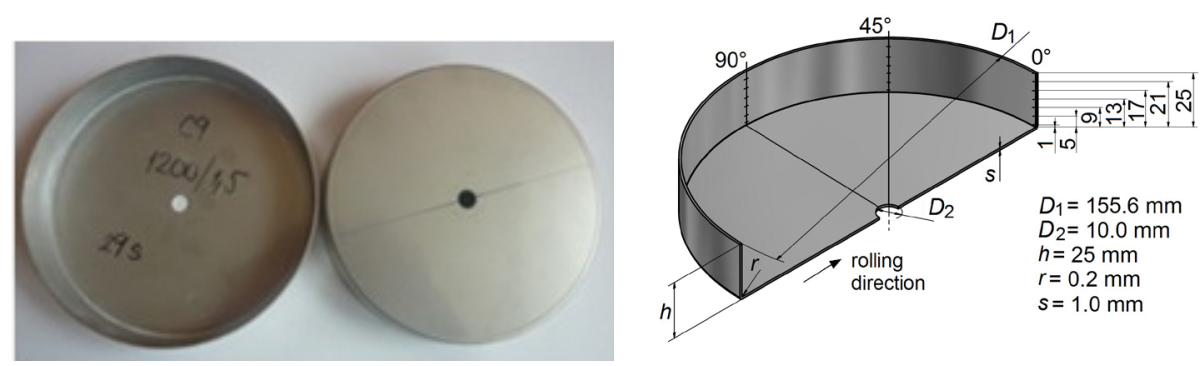

Fig. 1. Experimental sample 


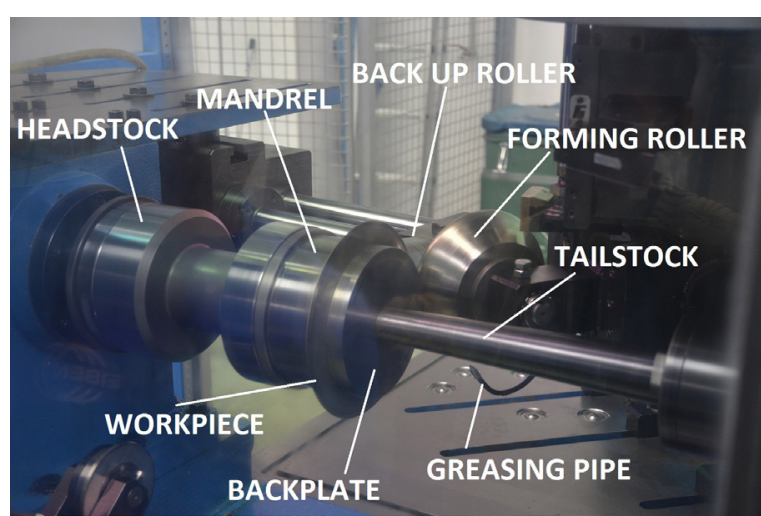

Fig. 2. Experimental set up

The roller geometrical parameters were: diameter $170 \mathrm{~mm}$, radius $\mathrm{R} 8$ and the angle between the axis of the roller and the axis of the mandrel was $35^{\circ}$ (Fig. 3).

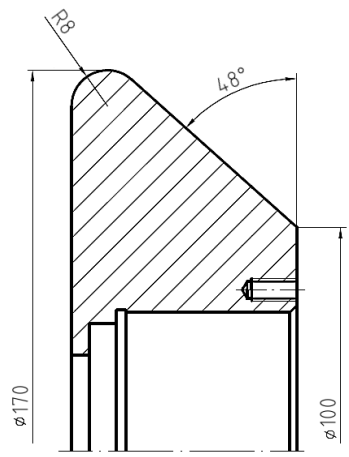

Fig. 3. Roller geometry

Three different mandrel speeds and three different levels of feed ratio (feed rate/mandrel speed) combined with the off-line designed linear, convex and concave roller path profiles were applied: nine movements towards the blank edge (forward passes) and one forward calibration pass. The detailed information about the first and last roller path of each path design is given in Fig. 4 and Table 2.

A review of experimental parameters and their levels is shown in Table 3. An experimental layout using full factorial design was used.

Table 2. Polynomial interpolation of roller path profiles

\begin{tabular}{ll}
\hline \multirow{2}{*}{ Convex } & $\mathrm{AD}: y=-0.006 x^{3}+0.042 x^{2}-0.701 x+99.637$ \\
& $\mathrm{EG}: y=-0.038 x^{2}+1.904 x+58.02$ \\
\hline \multirow{2}{*}{ Concave } & $\mathrm{AE}: y=0.004 x^{4}-0.136 x^{3}+1.846 x^{2}-11.709 x+116.999$ \\
& $\mathrm{Fl}: y=-0.0009 x^{3}+0.006 x^{2}+0.479 x-79.813$ \\
\hline \multirow{2}{*}{ Linear } & $\mathrm{AB}: y=-1.49 x+103.879$ \\
& $\mathrm{CD}: y=-0.257 x+74.402$ \\
\hline
\end{tabular}

Table 3. Process parameters and their levels

\begin{tabular}{lccc}
\hline Parameter & Level 1 & Level 2 & Level 3 \\
\hline Mandrel speed $n$ [rpm] & 400 & 800 & 1200 \\
\hline Feed ratio $f[\mathrm{~mm} / \mathrm{rev}]$ & 0.5 & 1 & 1.5 \\
\hline Tool path profile tpp $[-]$ & (1) concave & (2) linear & (3) convex
\end{tabular}
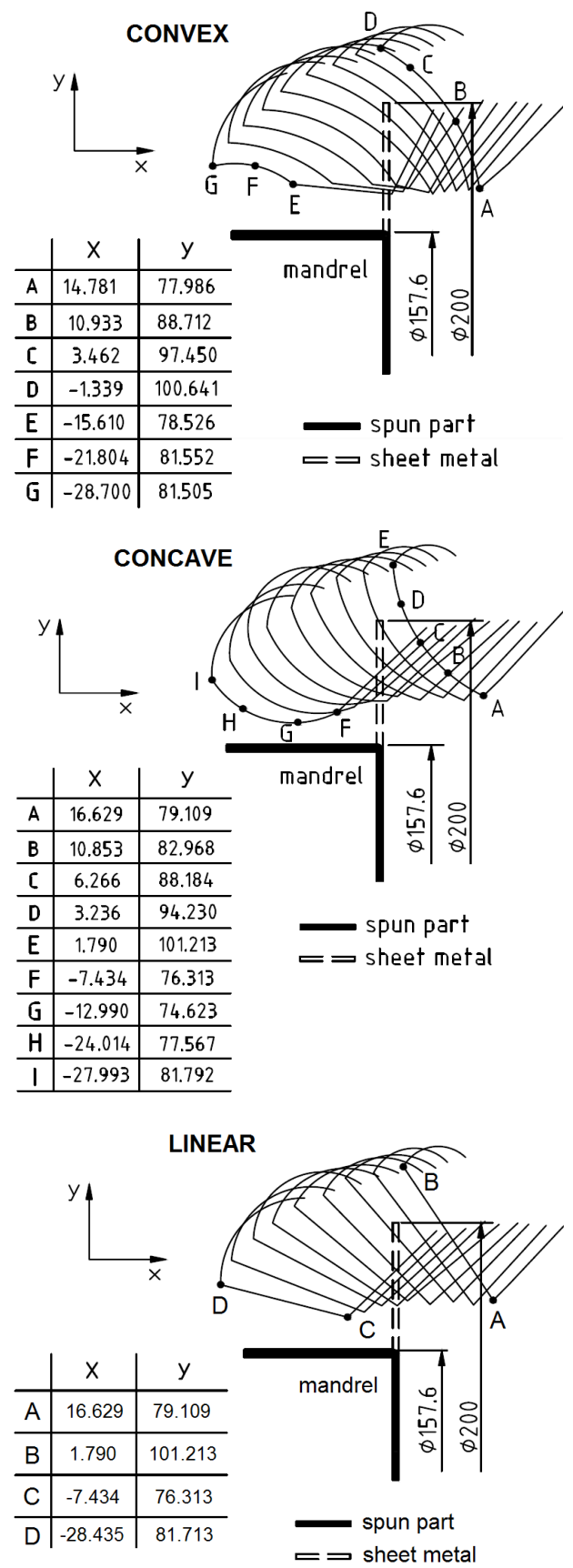

Fig. 4. Roller path profiles (Zero point [0;0]: intersection of mandrel axis with mandrel - workpiece interface plane) 


\subsection{Method of Wall Thickness Measurement}

For the experimental measurement of geometrical accuracy, a non-contact data capture method was used. The samples were digitized using the optical 3D system GOM ATOS II TripleScan SO MV 320 controlled by the software application GOM ATOS Professional v.7.4 [21] and [22]. The sample was scanned on a rotary table (10 scans rotated in $36^{\circ}$ increments) from both the inside and outside. For a correct evaluation of the specimens with respect to the rolling direction of the blank, a special jig, inserted into a hole at the bottom of the part, was used. The part surface was sprayed with white powder to provide a matt surface, as reflected light negatively influences the measurement accuracy. Next, non-coded reference points with diameters of $3 \mathrm{~mm}$ were stuck on the part's surface. The cloud of captured points was polygonized to obtain a triangulated surface model. Then the digital model was exported into an .stl file. The digitized part was compared with the reference CAD model using the software GOM Inspect v.8. The shape deviation between the digitized and CAD (reference) model was visualized using colour deviation plots (Fig. 5) and the thickness of part wall was recorded [23].

Thickness variation in this study means any difference between the part wall thickness and the thickness of the original sheet metal.

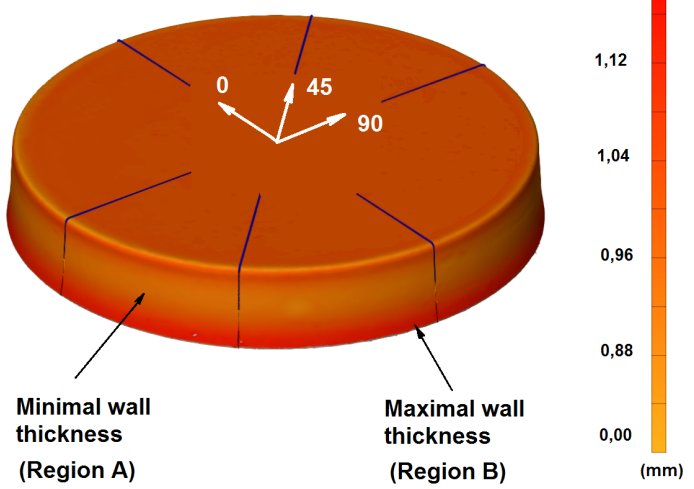

Fig. 5. Digitized model of the formed part with color map of thickness deviations

The thickness was measured in 7 places on the wall at distances of $(1,5,9,13,17,21$ and 25) $\mathrm{mm}$ from the part bottom, as shown in Fig. 1. The wall thickness measurement was done in three directions related to the rolling direction of the sheet: $0^{\circ}, 45^{\circ}$ and $90^{\circ}$. Due to the negligible differences in the part wall thickness depending on the rolling direction of the sheet, the mean values of the thickness measured in three directions were taken into account for the final evaluation.

The 3D optical measurement method has been validated by the contact measurement method using a digital micrometer with pointed measuring faces and a resolution of $0.001 \mathrm{~mm}$. The plot of deviations of measured data shows good agreement between the results of these measurements (Fig. 6).

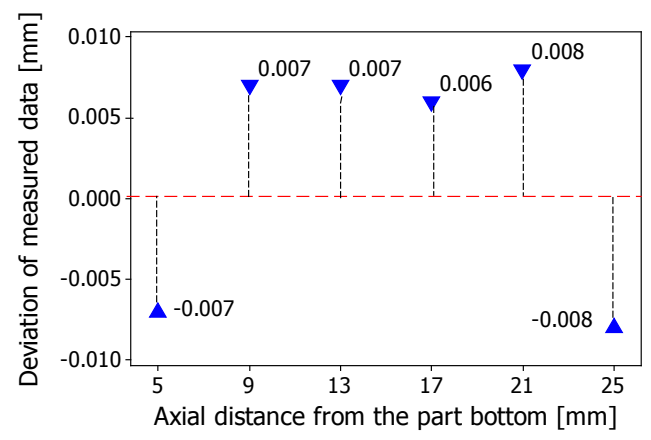

Fig. 6. The deviations in measured data of wall thickness obtained using a non-contact method (3D optical scanning technology) and a contact method (micrometer)

\section{RESULTS AND DISCUSSION}

The results of the experiments were analysed in order to estimate the contribution of individual parameters to part wall thickness variation. It was found that dependent on a combination of process parameters, the part wall thickness varies from $0.81 \mathrm{~mm}$ to 1.15 mm. As shown in Figs. 7 to 9, the maximal reduction in thickness was observed approximately half way up the part wall (Region A, situated at a distance of 13 $\mathrm{mm}$ from the part bottom) and the maximal increase in thickness was found at the open end of the formed part (Region B, situated at a distance of $25 \mathrm{~mm}$ from the part bottom).

In order to quantify the effects of the input factors studied and the interaction between them on wall thickness variation, an analysis of variance (ANOVA) using Minitab v. 17 software was performed. The Fisher's ratio ( $F$-ratio), which is the ratio between the variance due to the effect of a factor and the variance due to an error term, was used to measure the significance of the factor at the desired significance level. If the $F$-test value is greater than the tabulated $F$-test value, the process parameter is considered significant.

The results of the ANOVA and $F$-test for part wall thickness measured in the area with maximal thinning (axial distance of $13 \mathrm{~mm}$ from the cup bottom) and 


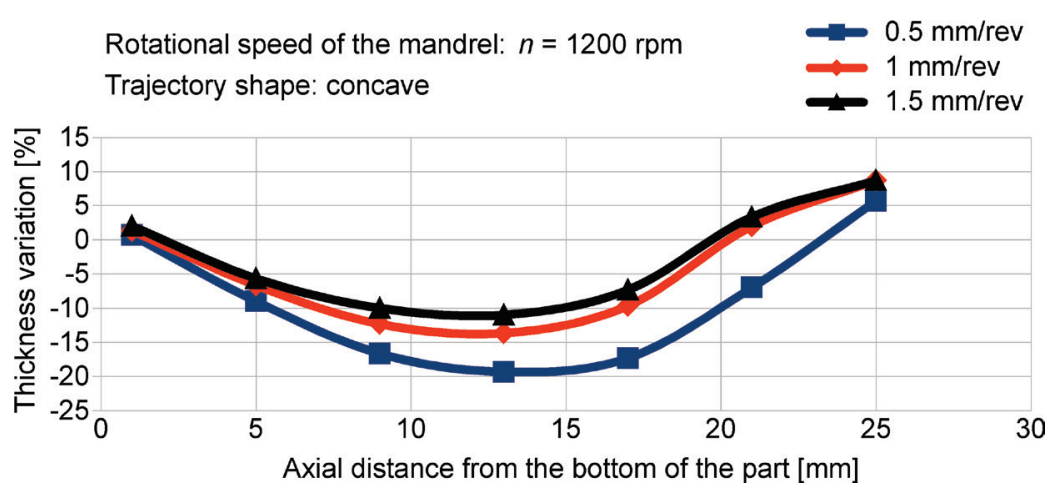

Fig. 7. Effect of feed ratio on wall thickness variation (Expanded uncertainty of the measure $U=3 \mu m(k=2$; confidence level $95 \%)$ )

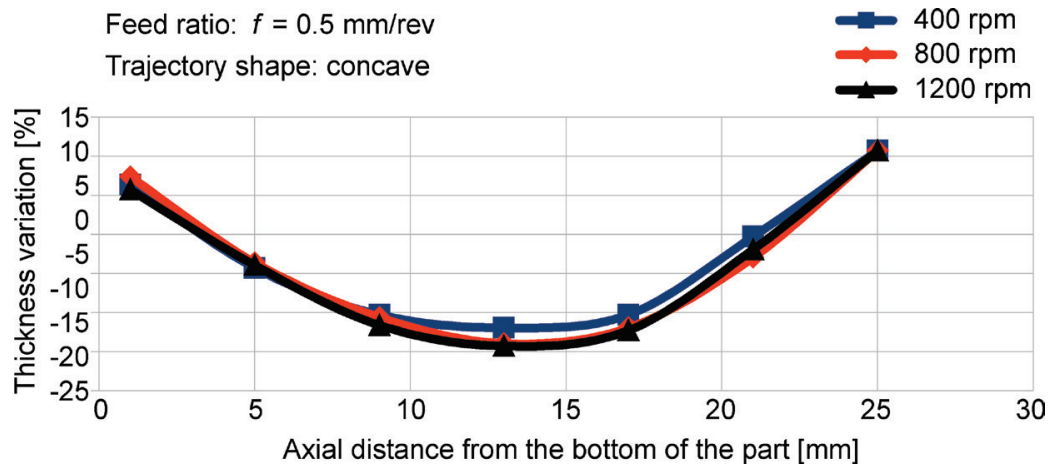

Fig. 8. Effect of mandrel speed on wall thickness variation (Expanded uncertainty of the measure $U=3 \mu \mathrm{m}(k=2$; confidence level $95 \%)$ )

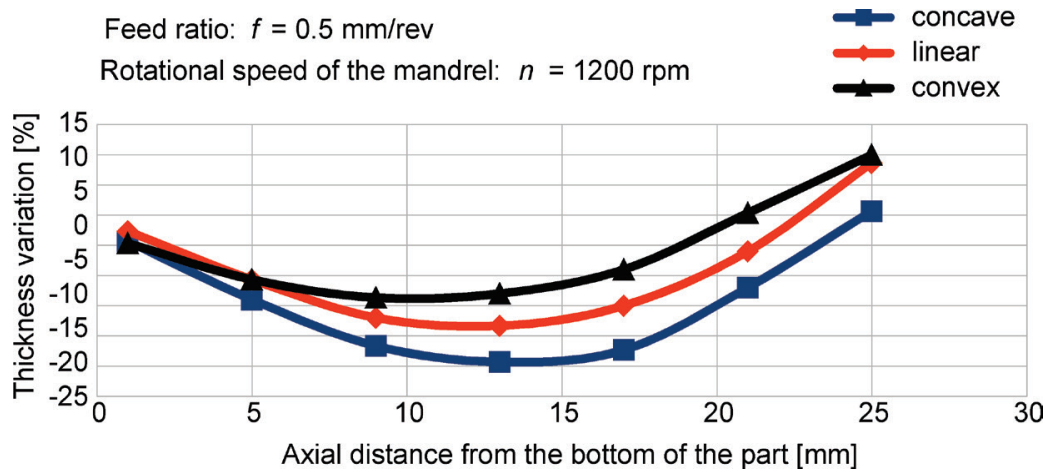

Fig. 9. Effect of tool path profiles on wall thickness variation (Expanded uncertainty of the measure $U=3 \mu m$ ( $k=2$; confidence level $95 \%)$ )

Table 3. ANOVA for thickness variation at a distance of $13 \mathrm{~mm}$ from cup bottom

\begin{tabular}{ccccc}
\hline Source & Sum of squares & DF & $F$-ratio & $p$-value \\
\hline$t p p$ & 371.949 & 2 & 533.90 & 0.000 \\
\hline$n$ & 4.776 & 2 & 6.85 & 0.018 \\
\hline$f$ & 148.296 & 2 & 212.86 & 0.000 \\
\hline$t p p \times n$ & 14.249 & 4 & 10.23 & 0.003 \\
\hline$t p p \times f$ & 7.616 & 4 & 5.47 & 0.020 \\
\hline$n \times f$ & 2.329 & 4 & 1.67 & 0.248 \\
\hline Error & 2.787 & 8 & & \\
\hline Total & 552.000 & 26 & \\
\hline \multicolumn{5}{c}{ Tabulated F-test values at 95 \% confidence level: }
\end{tabular}

$F(0.05 ; 2.8)=4.46 ; F(0.05 ; 4.8)=3.84 ; R^{2}$ adj $=94.29 \%$
Table 4. ANOVA for thickness variation at a distance of $25 \mathrm{~mm}$ from cup bottom

\begin{tabular}{ccccc}
\hline Source & Sum of squares & DF & $F$-ratio & $p$-value \\
\hline$t p p$ & 211.736 & 2 & 196.76 & 0.000 \\
\hline$n$ & 5.909 & 2 & 5.49 & 0.032 \\
\hline$f$ & 4.807 & 2 & 4.47 & 0.050 \\
\hline$t p p \times n$ & 0.676 & 4 & 0.31 & 0.861 \\
\hline$t p p \times f$ & 16.484 & 4 & 7.66 & 0.008 \\
\hline$n \times f$ & 1.191 & 4 & 0.55 & 0.703 \\
\hline Error & 4.304 & 8 & & \\
\hline Total & 245.107 & 26 & \\
\hline \multicolumn{5}{r}{ Tabulated F-test values at 95 \% confidence level: }
\end{tabular}

$\mathrm{F}(0.05 ; 2.8)=4.46 ; \mathrm{F}(0.05 ; 4.8)=3.84 ; R^{2}{ }_{\mathrm{adj}}=98.36 \%$ 
maximal thickening (axial distance of $25 \mathrm{~mm}$ from the cup bottom) are shown in Tables 3 and 4 .

The results of ANOVA show that all of the main input factors have statistically significant ( $p$-value: 0.01 to 0.05 ) or extremely significant ( $p$-value $<0.0001)$ influence on wall thickness variation. The most significant effect of tool path profile on the wall thickness variation is clearly seen in both measured areas. The thinning of the part wall is also affected by feed rate, mandrel speed has minimal effect. The thickening of the part wall is also influenced not only by the tool path profile, but also by the mandrel speed and feed ratio.
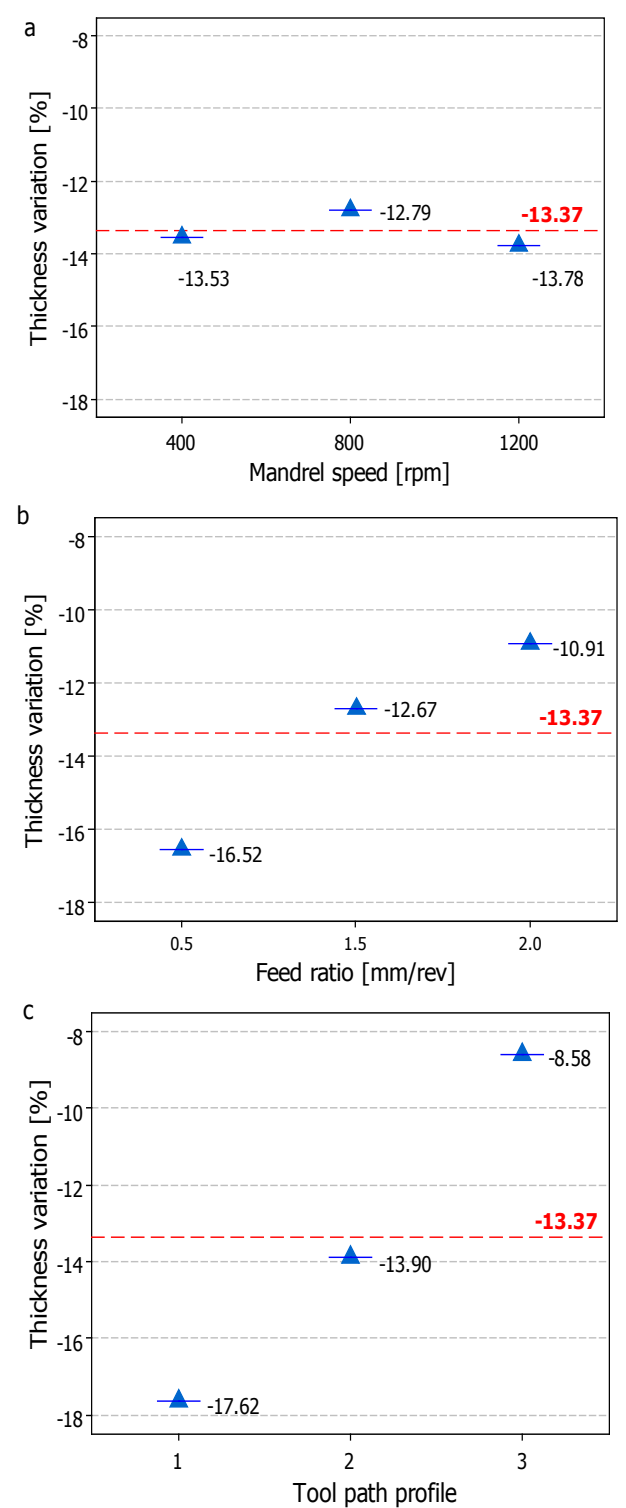

Fig. 10. The main effects of parameters on part wall thinning: a) mandrel speed, b) feed ratio and c) tool path profile
The results further showed that for part wall thinning there is a significant interaction among the input parameters, which is the tool path profile - feed ratio ( $p$-value: 0.01 to 0.05 ), and a very significant interaction among the input parameters, which is the tool path profile - mandrel speed ( $p$-value: 0.001 to 0.01 ). For part wall thickening there is only one very significant interactive influence: the tool path profile - feed ratio.

The determination coefficients, $R_{a d j}^{2}=94.29 \%$ for part wall thinning and $R^{2}{ }_{a d j}=98.36 \%$ for part wall thickening, demonstrate that the models are well fitted.
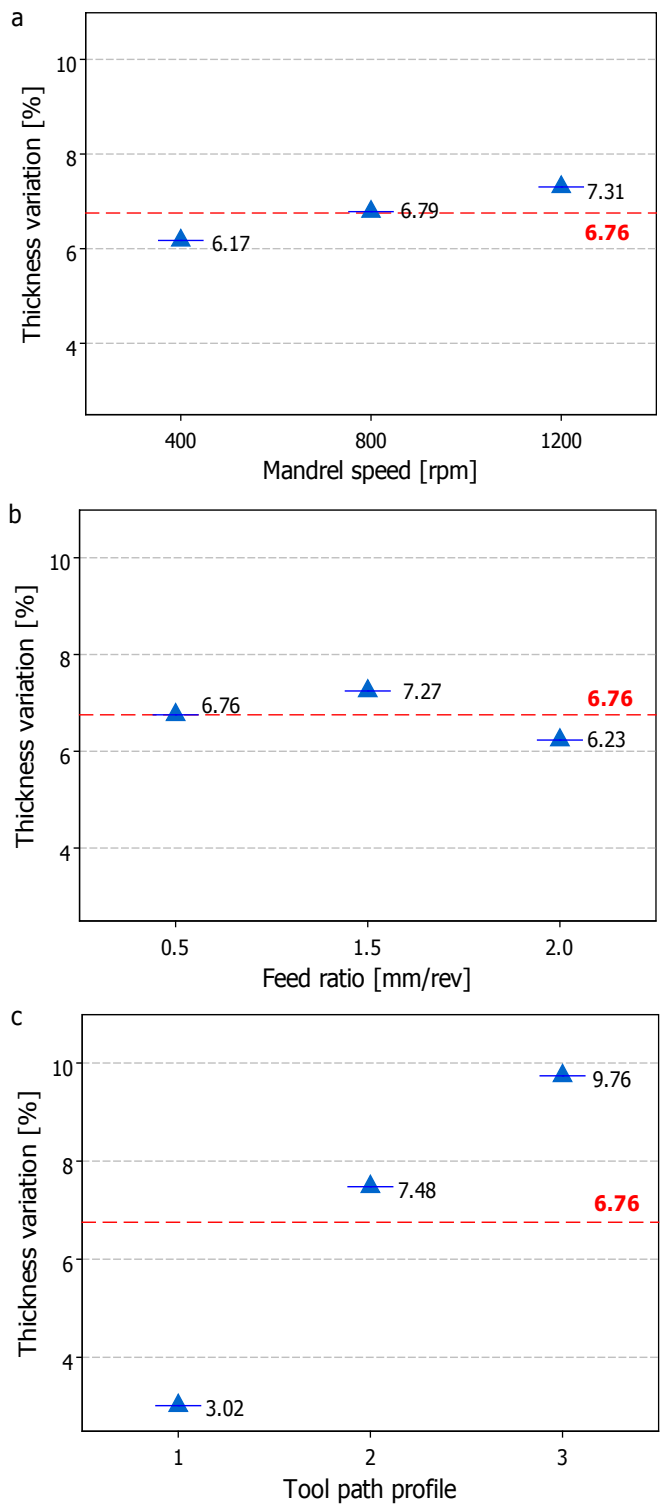

Fig. 11. The main effects of parameters on part wall thickening: a) mandrel speed, b) feed ratio and c) tool path profile 
Fig. 10 shows graphs of the effects of the input parameters on the part wall thickness in the area of maximal thinning. It is clear that maximal thinning was observed when the concave tool path profile was used. The convex tool path profile leads to minimal thinning. The graphs also show that higher values of feed ratio decrease the part wall thinning. There is a specific situation in the case of mandrel speed. Minimal thinning is reached when the mandrel speed is set to a value of $800 \mathrm{~min}^{-1}$. In both cases, when the mandrel speed value is higher or lower, a higher degree of part wall thinning is observed.

The effects of the main input parameters on part wall thickness in the area of maximal thickening are shown in Fig. 11. It can be seen that dominant thickening has been achieved for the convex tool path profile. The minimum value of thickening was recorded in the case where the concave tool path profile was applied. From the feed ratio point of view, minimal thickening was observed in the case where the maximal value of the feed ratio was applied and the maximal value of thickening was reported for the middle value of the feed ratio.

\section{CONCLUSIONS}

On the basis of the results obtained from this investigation and the statistical analysis, the following conclusions can be drawn:

1. The study confirms that 3D optical scanning technology can be useful in the evaluation of sheet metal parts thickness variation.

2. Among all the process parameters studied, the tool path profile is statistically the most significant factor and should be accurately controlled.

3. The concave tool path profile leads to a significant wall thickness reduction in Region A, but this roller trajectory gives minimal wall thickening on the open end of the part - Region $\mathrm{B}$, which is accompanied by the higher height of the part. Much higher tensile radial strains are produced if a concave roller path is applied and this is believed to be the main reason for intensive wall thinning.

4. It is clear that a high feed ratio helps to minimise wall thickness variations. It yields minimal thinning in Region A and minimal thickening in Region B. A lower feed ratio means that the tool acts on the workpiece over more revolutions, which in turn leads to higher shearing effects, an intensive flow of material to the open end of the part and an appreciable thinning of the wall.
5. The finding related to the tool path profile and feed ratio influence on wall thickness variation agrees with the results of other authors who have studied this problem experimentally and by applying FE analysis for other types of spun part materials (mild steel, aluminium) [12], [14], [17] and [24].

6. The influence of mandrel speed on wall thickness variation in both regions of the part wall is only minimal. The findings can be expressed thus: mandrel speed has negligible influence on axial and radial force components [10], therefore radial and thickness strain is minimal.

7. For minimal variation in spun part wall thickness it is recommended to apply a convex tool path in combination with higher values of the feed ratio.

\section{ACKNOWLEDGEMENTS}

The authors wish to acknowledge the financial support provided by the Ministry of Education, Science, Research and Sport of the Slovak Republic project VEGA $1 / 0669 / 15$ and the research project Manunet: FormTool MANUNET-2014-11283. The authors also wish to thank MSc. E. Eiben and MSc. G. Eiben of Eiben Co. Ltd. for their technical assistance.

\section{REFERENCES}

[1] Music, O., Allwood, J.M., Kawai, K. (2010). A review of the mechanics of metal spinning. Journal of Materials Processing Technology, vol. 210, no. 1, p. 3-23, D0l:10.1016/j. jmatprotec.2009.08.021.

[2] Xia, Q., Xiao, G., Long, H., Cheng, X., Sheng, X. (2014). A review of process advancement of novel metal spinning. International Journal of Machine Tools and Manufacture, vol. 85, p. 100121, D0I:10.1016/j.ijmachtools.2014.05.005.

[3] Härtel, S., Laue, R. (2016). An optimization approach in noncircular spinning. Journal of Materials Processing Technology, vol. 229, p. 417-430, D0l:10.1016/j.matprotec.2015.09.003.

[4] Wong, C.C., Dean, T.A., Lin, J. (2003). A review of spinning, shear forming and flow forming processes. International Journal of Machine Tools and Manufacture, vol. 43, no. 14, p. 1419-1435, DOI:10.1016/S0890-6955(03)00172-X.

[5] Tschätsch, H. (2005). Metal Forming Practise. Springer, Heidelberg.

[6] Härtel, S., Awiszus, B. (2014). New processing technologies of incremental sheet metal forming. Procedia Engineering, vol. 81, p. 2311-2317, D0I:10.1016/j.proeng.2014.10.326.

[7] Brabie, G., Chirita, B., Albut, A. (2015) Minimization of sheet thickness variation and other defects of mini drawn parts using a blank holder plate made from concentric rings. Precision Engineering, vol. 42, p. 311-320, Dol:10.1016/j. precisioneng.2015.03.011. 
[8] Quigley, E., Monaghan, J. (2000). Metal forming: an analysis of spinning processes. Journal of Materials Processing Technology, vol. 103, no. 1, p. 114-119, Dol:10.1016/S09240136(00)00394-0.

[9] Kawai, K., Hayama, M. (1987). Roller pass programming in conventional spinning by NC spinning machine. Advanced Technology of Plasticity, vol. 2, p. 711-718, D0l:10.1007/9783-662-11046-1_4.

[10] Wang, L., Long, H., Ashley, D., Roberts, M., White, P. (2011). Effects of the roller feed ratio on wrinkling failure in conventional spinning of a cylindrical cup. Journal of Engineering Manufacture, vol. 225, no. 11, p. 1991-2006, DOI:10.1177/0954405410396024.

[11] Sugar, P., Šugárová, J., Morovič, L., Zemko, P. (2012). Analysis of dimensional accuracy of spun parts by Taguchi approach. Applied Mechanics and Materials, vol. 217-219, p. 24232426, Dol:10.4028/www.scientific.net/AMM.217-219.2423.

[12] El-Khabeery, M.M., Fattouh, M. El-Sheikh, M.N., Hamed, O.A. (1991). On the conventional simple spinning of cylindrical aluminium cups. International Journal of Machine Tool and Manufacture, vol. 31, no. 2, p. 203-219, Dol:10.1016/08906955(91)90005-N.

[13] Gao, C.Y., Fang, Y.T. (2005) Investigation on the factors influencing the thickness distribution of superplastic-formed components. Journal of Zhejiang University, Science A, vol. 6 , no. 7, p. 711-715, Dol:10.1631/jzus.2005.A0711.

[14] Kang, D.-C., Gao, X.-C., Meng, X.-F., Wang, Z.-H. (1999). Study on the deformation mode of conventional spinning of plates. Journal of Materials Processing Technology, vol. 91, no. 1-3, p. 226-230, DOI:10.1016/S0924-0136(98)00447-6.

[15] Liu, J.H., Yang, H., Li, Y.Q. (2002). A study of the stress and strain distributions of first-pass conventional spinning under different roller-traces. Journal of Materials Processing Technology, vol. 129, no. 1-3, p. 326-329, D0l:10.1016/ S0924-0136(02)00682-9.

[16] Hayama, M., Kudo, H., Shinodura, T. (1970). Study of the pass schedule in conventional simple spinnning. Bulletin of Japan
Society of Mechanical Engineering, vol. 13, no. 65, p. 13581365, D0l:10.1299/jsme1958.13.1358.

[17] Wang, L., Long, H. (2011). A study of effects of roller path profiles on tool forces and part wall thickness variation in conventional metal spinning. Journal of Materials Processing Technology, vol. 211, no. 12, p. 2140-2151, D0l:10.1016/j. jmatprotec.2011.07.013.

[18] Essa, K., Hartley, P. (2009) Numerical investigation on the effect of roller-trace in dual pass cup spinning. Journal for Technology of Plasticity, vol. 34, no. 1-2, p. 15-25.

[19] Essa, K., Hartley, P. (2010). Optimization of conventional spinning process parameters by means of numerical simulation and statistical analysis. Journal of Engineering Manufacture, vol. 224, no. 11, p. 1691-1705, DOI:10.1243/09544054JEM1786.

[20] Polyblank, J.A., Allwood, J.M. (2015) Parametric toolpath design in metal spinning. CIRP Annals - Manufacturing Technology, vol. 64, no. 1, p. 301-304, D0l:10.1016/j. cirp.2015.04.077.

[21] ATOS II Rev. 02: User Manual - Hardware. (2010). GOM $\mathrm{GmbH}$.

[22] Brajlih, T. Tasic, T., Drstvensek, I., Valentan, B. Hadzistevic, M., Pogacar, V., Balic, J., Acko, B. (2011). Possibilities of using three-dimensional optical scanning in complex geometrical inspection. Strojniški vestnik - Journal of Mechanical Engineering, vol. 57, no. 11, p. 826-833, D0l:10.5545/svjme.2010.152.

[23] Šugár, P., Šugárová, J. and Morovič, L. (2008) Application of 3D optical scanning for the shape accuracy analysis of machine parts produces by multi-pass metal spinning. Annals of DAAAM for 2008 \& Proceedings of the 19th International DAAAM Symposium; Intelligent Manufacturing \& Automation: Focus on Next Generation of Intelligent Sytems and Solutions, p. 1331-1332.

[24] Runge, M. (1994). Spinning and Flow Forming. (D. H. Pollitt, Trans), Leifield GmbH. 